Please quote as: Leimeister, J. M.; Böhm, M. \& Yetton, P. (2012): Managing IT in a Business Unit Divestiture. In: MIS Quarterly Executive, Ausgabe/Number: 1, Vol. 11, Erscheinungsjahr/Year: 2012. Seiten/Pages: 37-48. 


\section{Managing IT in a Business Unit Divestiture ${ }^{1,2}$}

Jan Marco Leimeister

Kassel University

(Germany)

\section{Markus Böhm \\ Technische Universität München (Germany)}

\section{Philip Yetton \\ Australian School of \\ Business (Australia)}

\section{Executive Summary}

The divestiture of a business unit-also known as a "carve-out"-is a common strategy used by multi-business organizations to adjust their business portfolios in response to a change in business strategy, and legal or regulatory pressures. In a typical divestiture, systems that were integrated in the past to deliver seamless and efficient IT operations must be pulled apart under demanding time and regulatory compliance constraints. Yet, as with many merger and acquisition projects, CIOs involved in carve-out projects that include critical dependencies on IT systems may be excluded from the due-diligence process. This article presents a case study of a carve-out project to divest a business unit within a global multi-business company. In addition to the lessons learned about unique aspects of managing IT for a business unit divestiture, this case sheds light on how CIOs can create divestiture-ready IT environments and thus better prepare their organizations for IT carve-out projects.

\section{DIVESTITURES AND THEIR CHALLENGES}

Acquiring and divesting business units are standard techniques of strategic management. Moreover, an acquisition by one organization is often a divestiture by another. Reasons for divestitures include changes in organizational focus or strategy, weak economic performance or a need for capital. ${ }^{3}$ Antitrust regulations or other contractual obligations are also reasons for organizations to sell business units. In 2009 , more than 12,000 divestitures were conducted worldwide with a total value in excess of $\$ 600$ billon. $^{4}$

As in merger and acquisition (M\&A) projects, the role of the IT function in a divestiture (also referred to as a "carve-out") can be complex and have serious financial and strategic implications for both the seller and the buyer. The case of Roche Pharmaceuticals illustrates the potential financial implications: when selling its vitamins division, Roche underestimated the cost of disentangling the IT by a factor of twenty. ${ }^{5}$

To highlight some of the risks that a business faces in achieving its goals from a major divestiture, and some of the lessons learned, we describe how Gamma Consulting (GC), part of a major multi-business company (the GAMMA Group), responded to the challenges of carving-out a tightly integrated business unit that was sold to another company. ${ }^{6}$ Our focus is on the IT component of the carve-out project, organized as an IT workstream, and staffed with a mix of internal and external resources. (For details

1 Bill Kettinger is the accepting senior editor for this article.

2 We would like to thank Carol Brown, Bill Kettinger, Helmut Krcmar, Jeanne Ross and Joan Spiller for their valuable comments on earlier drafts of this article.

3 Leimeister, S., Leimeister, J. M., Fähling, J. and Krcmar, H. "Exploring Success Factors for IT Carve Out Projects," Proceedings of the 16th European Conference on Information Systems, 2008, Galway, Ireland, pp. 1764-1776. Villalonga, B., and McGahan, A. M. "The choice among acquisitions, alliances, and divestitures," Strategic Management Journal (26:13), 2005, pp. 1183-1208.

4 “Divestiture M\&A News: 2010 Divestiture Survey Report and Year in Review," Deloitte Quarterly Divestiture Report, 2011, Deloitte Corporate Finance.

5 Applegate, L. M., Watson, E. and Vatz, M. "Royal DSM N.V.: Information Technology Enabling Business Transformation," Harvard Business School, Case \# 807167-HCB-ENG, 2007.

6 The names of all the companies and business units in this case have been disguised. 


\section{Figure 1: Carve-Out Phases and Milestones}

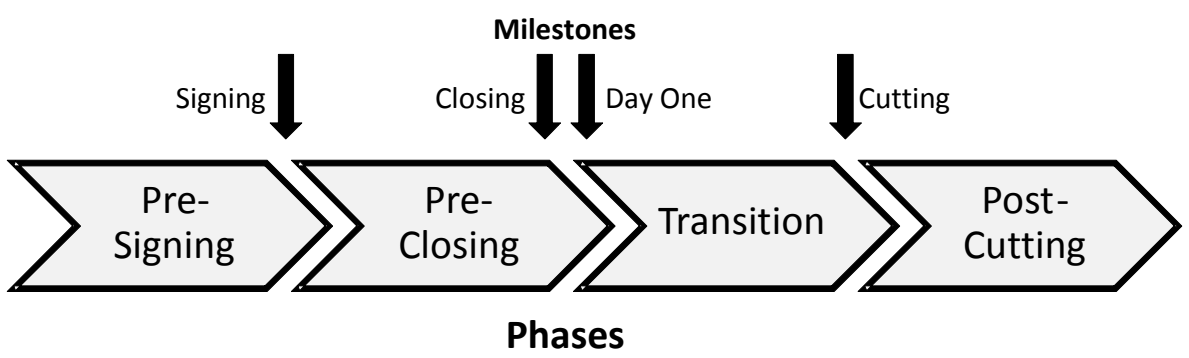

about our data collection methods for this case study, see the Appendix.)

First, we briefly describe the typical phases and milestones of an IT carve-out project. We then introduce the case company and the business unit that was divested, some aspects of the due diligence and contract negotiations with the buyer that could have benefited from more IT leader involvement and the IT landscape within GAMMA Group that influenced the complexity of the IT carve-out project. Next, we present some specific challenges that GC's CIO and his team faced after the contract was signed with the buyer. Finally, based on our multi-year study of this company and other divestiture case studies that we have conducted, we share some lessons learned about how to both manage a successful IT carve-out project and design a divestiture-ready IT environment in general.

\section{TYPICAL CARVE-OUT PROJECTS}

An IT carve-out project is typically organized in four phases (see Figure 1). It begins with a Pre-Signing phase, including all negotiations and preparations before the legal divestiture contract is signed. A "data room" - a physical room with an extensive volume of folders containing confidential material, including, for example, financial data, contracts, and customer and employee information - is established for the buyer to conduct due diligence on which to base a contract.

The separation of the carve-out object (the business unit) formally starts after the signing of the contract and, where relevant, approval for the transaction has been given by the regulatory authorities. In this PreClosing phase, separation tasks are planned and the systems are prepared for Day One, when the carve-out object becomes an independent entity and the property of the buyer. However, since full separation of IT systems cannot always be achieved at this stage due to the complexity of the seller's IT landscape, a two-step process is frequently adopted. Before Closing, there is a logical separation of important information systems (e.g., financial reporting) on the same hardware, followed by a Transition phase in which the bulk of the separation work takes place. This phase ends with the Cutting milestone, which is when the physical separation of the carve-out object from the seller actually takes place.

Because the buyer is the official owner of the carve-out object after Closing, transitional service agreements (TSAs) are used, where necessary, to ensure and control the provisioning of IT services by the seller to the carve-out object. Even after the Cutting milestone, a buyer may continue to use IT systems in the seller's network to gather historical data or as backup in the case of system failure during the IT integration. Thus, TSAs and final separation activities frequently continue in the Post-Cutting phase. On completion of the Post-Cutting phase, the carve-out object ceases to have any relationship with its former parent.

At first sight, TSAs appear to be simple and effective solutions through which the seller provides temporary IT support to the carve-out object on behalf of the buyer. However, they frequently cause business, technical and motivational problems. First, they are costly (because the seller cannot turn off otherwise redundant IT systems) and strategically restrictive (IT-based strategic initiatives are put on hold because the seller is locked into the IT status quo). Second, the seller essentially acts as a service provider to the buyer, which requires technical and other capabilities that are different from those that were needed previously to provide similar support internally. This is a major challenge for a seller with limited capabilities in and experience of providing external 


\section{Figure 2: GC's Business Units}

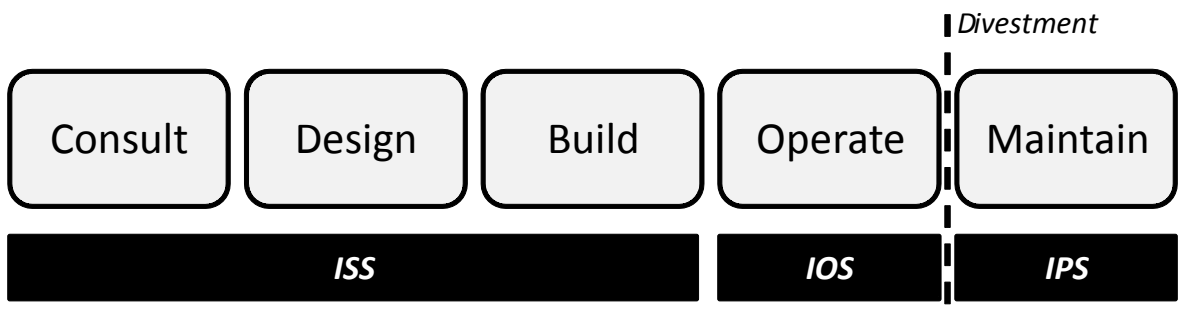

IT services. ${ }^{7}$ Finally, the collaboration required to manage a complex set of TSAs is difficult to sustain; there is limited mutuality at this late stage in a carveout project.

\section{BUSINESS UNIT CARVE- OUT PROJECT AT GAMMA CONSULTING}

GAMMA Group is a global multi-business organization, operating in more than 160 countries. In the year of the divestiture, it employed 370,000 people worldwide, generating revenue of more than $€ 70$ billion ( $\$ 91$ billion), with a profit of over $€ 2.4$ billion ( $\$ 3.1$ billion). Gamma Consulting was part of the Digital Processing and Transmitting business group within GAMMA Group. GC delivered a broad portfolio of multi-vendor IT solutions and services to more than 10,000 customers in the private and public sectors, generating revenue of $€ 3.8$ billion ( $\$ 4.9$ billion) in the year before the divestiture. Its portfolio included services ranging from consulting and system integration, to the management and operation of business IT infrastructure and business processes.

To improve its profitability, GAMMA Group embarked on a major restructuring project with the objective of achieving a $5 \%-6 \%$ operating profit margin for each of its businesses within 24 months. At that time, GC was expected to lose $€ 109$ million (\$141.5 million) for the year, down from a profit of $€ 40$ million ( $\$ 52$ million) the year before - mostly due to increased price pressure from new competitors entering GC's most important markets.

7 See Du, K. and Tanriverdi, H. "The performance effects of transitional IT services in corporate spin-offs," 2010, Proceedings of the International Conference on Information Systems (ICIS), St. Louis, p. 248.
GC comprised three business units that covered the IT lifecycle (see Figure 2). The IT Solution Services (ISS) business delivered consulting services and designed customer solutions, including, for example, SAP system integration. The IT Operations Services (IOS) business managed IT operations on behalf of its customers, including both the outsourcing of IT business processes and the management of data centers, desktop environments, LAN/WAN and call centers. The IT Product Services (IPS) business provided maintenance and infrastructure services, including platform-independent IT infrastructure services and solutions that addressed customers' high availability, consolidation, migration and lifecycle management requirements.

The restructuring solution for GC was to divest its IPS business. At that time, IPS employed 2,300 people worldwide, with a global network of 60,000 service partners and system integrators in 140 countries. After considering various sales options, GAMMA Group announced that it was selling IPS to I\&G, a 50:50 independent joint venture between GAMMA Group and International Computer Industries. Prior to the sale, I\&G had been a hardware supplier to GAMMA Group and especially to GC. Selling IPS to a competitor would have posed a serious potential threat to $I \& G$, as the new owner would have acquired both major service contracts with GC's own customers and access to valuable intellectual property.

The sale of IPS to I\&G generated several IT carveout challenges. Within GAMMA Group, core systems mandated for all countries were centralized. For example, the IT system for corporate group control, reporting and financials was operated and maintained at the corporate level. This layer sat over the various SAP ERP systems within GAMMA Group. GC had its own SAP ERP system and a portfolio of centralized applications used by its business units - such as order 


\section{Table 1: Examples of Centralized and Local Applications Used by IPS}

\begin{tabular}{|l|l|l|l|l|}
\hline \multicolumn{2}{|c|}{} & \multicolumn{1}{c|}{$\begin{array}{c}\text { IPS } \\
\text { (Carve-out object) }\end{array}$} & $\begin{array}{c}\text { Gamma Consulting } \\
(G C)\end{array}$ & \multicolumn{1}{c|}{ GAMMA Group } \\
\hline \multirow{2}{*}{$\begin{array}{l}\text { Locus of } \\
\text { Control }\end{array}$} & Local & Sales and support & Accounting and control \\
\cline { 2 - 5 } & Central & Spare parts ordering & $\begin{array}{l}\text { Scheduling and billing } \\
\text { of expenses for mobile } \\
\text { technicians }\end{array}$ & $\begin{array}{l}\text { E-mail and groupware, and } \\
\text { group-wide data warehouse }\end{array}$ \\
\hline
\end{tabular}

scheduling and billing. In addition, each business unit mandated use of its own applications. Finally, some country subsidiaries within GAMMA Group, which sold and delivered products and services for business units such as IPS, ran their own SAP ERP systems.

Table 1 provides examples from IPS's application landscape, illustrating the range of centralized and local applications used by the IPS business unit. While GAMMA Group had formal approval processes for the selection, adoption and usage of IT systems, the IT organizations at corporate level, and within GC and the IPS business unit, gave country subsidiaries a high degree of freedom to customize systems to support local legal requirements and pricing issues. For example, IPS allowed some country subsidiaries to customize the IPS sales and support systems.

About six weeks before the official announcement of the sale of IPS, a confidential internal kick-off meeting was called, with key staff from the relevant functions and businesses in GAMMA Group, to begin preparation for the carve-out project. The project was organized into 10 workstreams, including the IT workstream. The HR workstream was responsible for all personnel issues, including negotiations about which employees would move to I\&G. The Customer Contracts workstream negotiated the transfer of customers from IPS to I\&G, and the Legal workstream was responsible for ensuring conformance to the relevant regulations in the affected countries. The role of the Customer Contracts workstream was especially important because the sale of IPS was to a business partner, and customers of IPS were frequently also customers of GC's other business units (ISS and IOS).

The leader of the IT workstream recognized early on that success would depend on its collaboration with the other workstreams:
"The carve-out project is complex. IT is only one workstream, although an important one. As one of the first steps, we will define the interfaces between our IT workstream and the other workstreams (including, for example, HR, Customer Contracts and Legal) to ensure good information flow."

The IT workstream was initially staffed with three experienced IS executives from within GC and GAMMA Group. During the Pre-Signing phase, the team began collecting information about IPS's IT environment to support the due-diligence process, evaluating alternative carve-out strategies and developing a project plan for the IT carve-out workstream. All IT workstream team members signed non-disclosure agreements and were designated "insiders" for financial regulatory purposes. This meant they were precluded from discussing their activities during the Pre-Signing phase with anyone outside the team. This made it difficult to acquire information. They had to find plausible alternative reasons for data collection, to avoid creating rumors.

\section{Due Diligence and Contract Negotiation}

GC also established a Deal team, consisting of lawyers, consultants and internal managers, to prepare for and conduct the contract negotiations with the buyer (I\&G). Although GC was aware that IT would be important in the carve-out project, it did not appoint its CIO or any other representative with an IT background to its Deal team.

The Deal team pulled together the due-diligence information required by the prospective buyer, who was given access to selected staff and the data room. The information provided on the IT environment focused on the centralized IT infrastructure, including an inventory of the systems that supported the major 


\section{Figure 3: IT Workstream Organization}

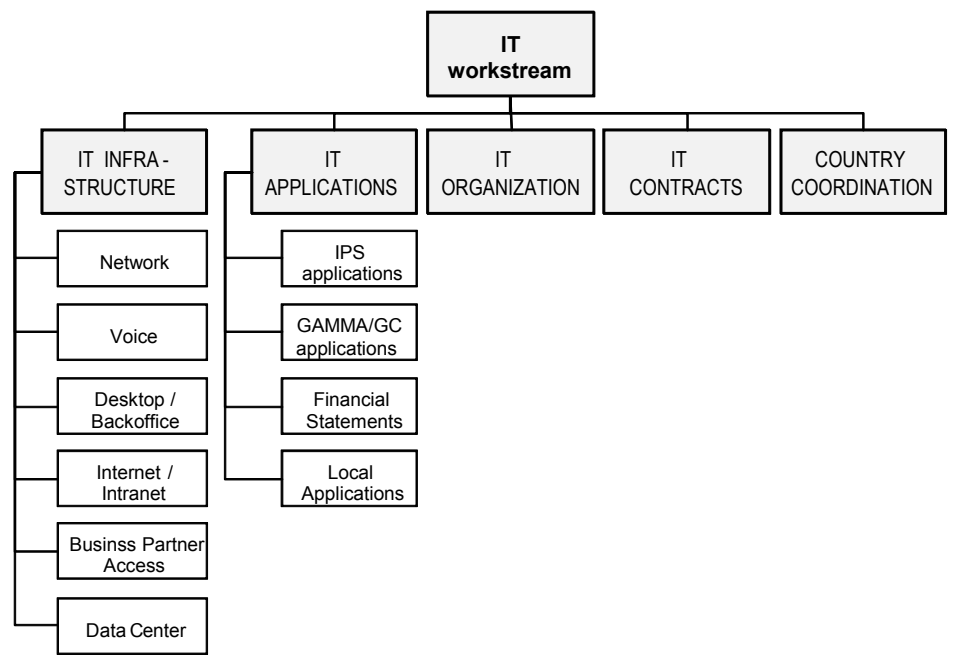

business processes in the IPS business unit, together with information about their operational costs.

In contrast, I\&G did appoint people with IT backgrounds to its Deal team. From its IT due diligence, $I \& G$ gained a good understanding of the centralized IT environment, but remained concerned about the absence of information describing the local IT environments in the country subsidiaries, and suspected hidden risks and costs. As a consequence, during the contract negotiation, I\&G added several IT issues to the negotiating table.

According to the IT workstream leader at GC:

\begin{abstract}
"When I\&G brought IT issues to the table, our Deal team approached me on a Friday afternoon and asked me for a quick review within two hours. As a consequence, several IT issues were negotiated in favor of $I \& G$, which increased the carve-out costs to GC or led to renegotiations."
\end{abstract}

An example was the IT change request application that had been developed by the IPS business unit and was used elsewhere in GC to manage IT projects. In the original negotiations, the application was sold to $I \& G$, without retaining a license agreement for its ongoing use in GC. Difficult and time-consuming renegotiations had to be conducted later for $\mathrm{GC}$ to obtain the right to continue using this application in its other businesses. The sales contract also imposed all costs related to the IT carve-out on GC; the IT carveout costs incurred by the buyer were deducted from the sales price.

\section{The IT Workstream}

The IT workstream was initially organized into four sub-streams:

1. IT Infrastructure, including all network, voice, desktop PC, data center and business partner access issues.

2. IT Applications, including data, which dealt with issues regarding IPS applications, specific $\mathrm{GC}$ applications, financial reporting and local applications.

3. IT Organization, including HR issues, which vetted IT staff, including key personnel, and prepared their transfer from GAMMA Group or $\mathrm{GC}$ to $\mathrm{I} \& \mathrm{G}$.

4. IT Contracts, which was responsible for the identification and assessment of licenses and legal issues concerning the transfer of software and hardware from the seller to the buyer.

A fifth sub-stream was added after the complexities involved with local IT sites in country subsidiaries emerged:

5. Country Coordination, which managed the carve-out impacts within country subsidiaries.

Figure 3 shows the final IT workstream organization. When the carve-out project was officially launched, the IT carve-out workstream was staffed with 20 people. After the Closing milestone, and throughout the Transition phase, more than 50 people worked in the IT workstream. 


\section{Figure 4: IT Workstream Plan}

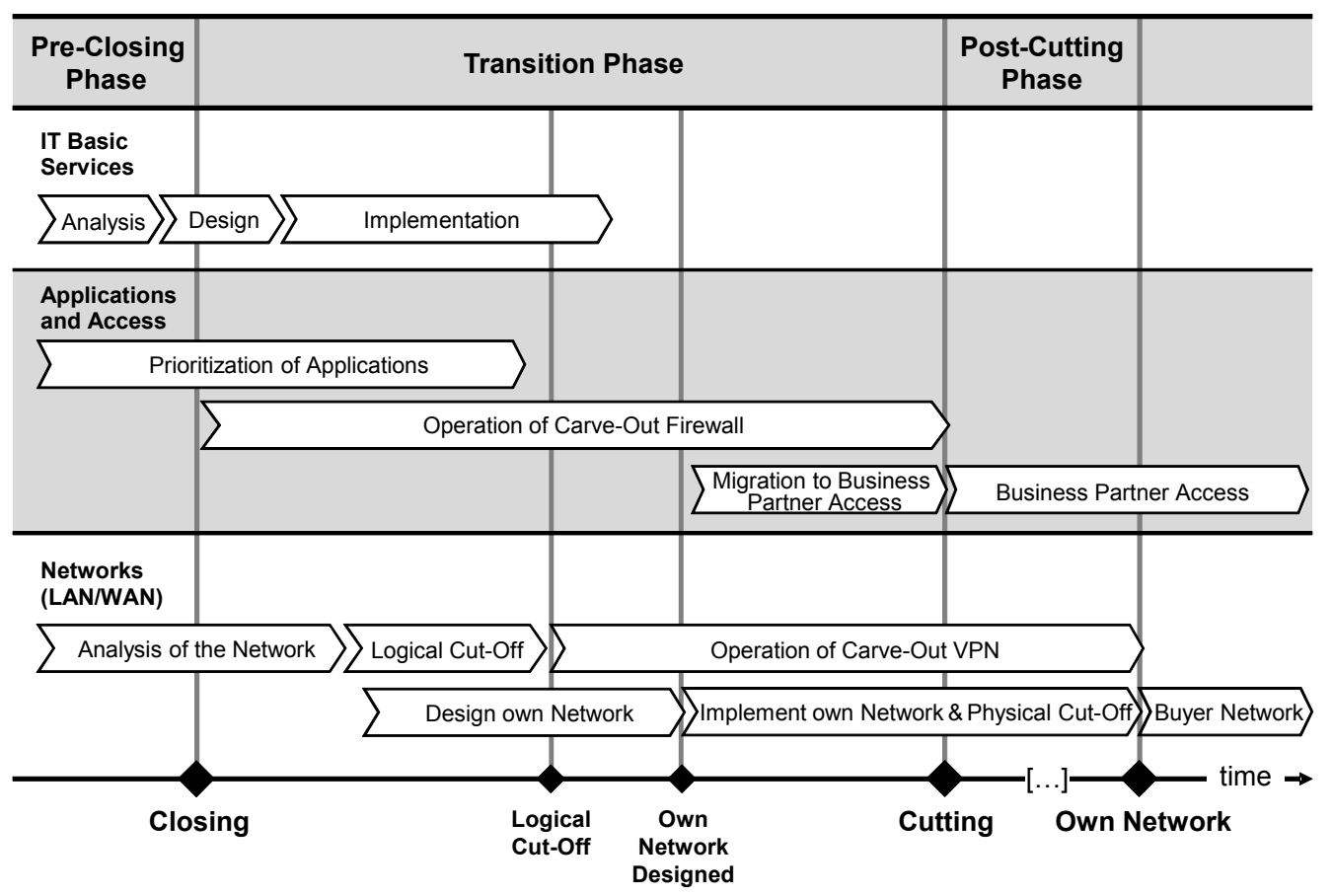

An initial IT project plan, with time and resource dependencies, was developed for internal use in GAMMA Group and GC, and for communicating with the buyer during the Pre-Signing phase. From its experience of other carve-outs, GAMMA Group and GC had learned that only a few legally critical information systems could be physically separated before the Closing milestone; full IT separation is rarely achieved before the Cutting milestone (see Figure 1).

Before the Closing milestone, the local and wide-area networks and basic IT services-including e-mail and office applications - were analyzed, and applications prioritized and scheduled. After Closing, a carveout firewall was set up and the logical cut-off of the networks started. In parallel, a new IPS network was designed. After the Cutting milestone, a Business Partner Access Plan enabled the buyer to access the network and certain services from GC to keep IPS operational during the Post-Cutting Phase. This access was regulated through TSAs until the carve-out object was transferred to its own network. Figure 4 shows some of the critical tasks in the IT workstream plan.

Figure 5 shows an in-depth excerpt from the IT workstream plan for the IT sub-streams in Figure 3.
IT Infrastructure. The separation of the WAN, voice and back-office services was essential to satisfy compliance requirements and to deliver IT services to the buyer at Closing, throughout the Transition phase and until the completion of the carve-out. Since both GAMMA Group and I\&G used Microsoft and SAP technology for e-mail, groupware and enterprise resource planning, the transfer of these support services was less problematic than it could otherwise have been. Nevertheless, while IPS employee mailboxes were encapsulated and, therefore, could easily be transferred to I\&G, IPS employees previously were able to store documents and post comments to GAMMA's groupware platform. This made it difficult to identify and separate all relevant IPS employee documents, transfer them to the I\&G groupware system and delete them from the GAMMA groupware system. Despite these separation difficulties, the use of standard applications made the system migration easier, and also eased the transfer and integration of IT support staff from IPS to I\&G.

Applications and Data. As described earlier, the information system interdependencies were a critical IT challenge in the IPS carve-out. In the words of the IT workstream leader:

"Some IT systems at IPS are hosted on the
GAMMA Group IT platform and are highly
integrated with other GAMMA Group IT 


\section{Figure 5: IT Workstreams}

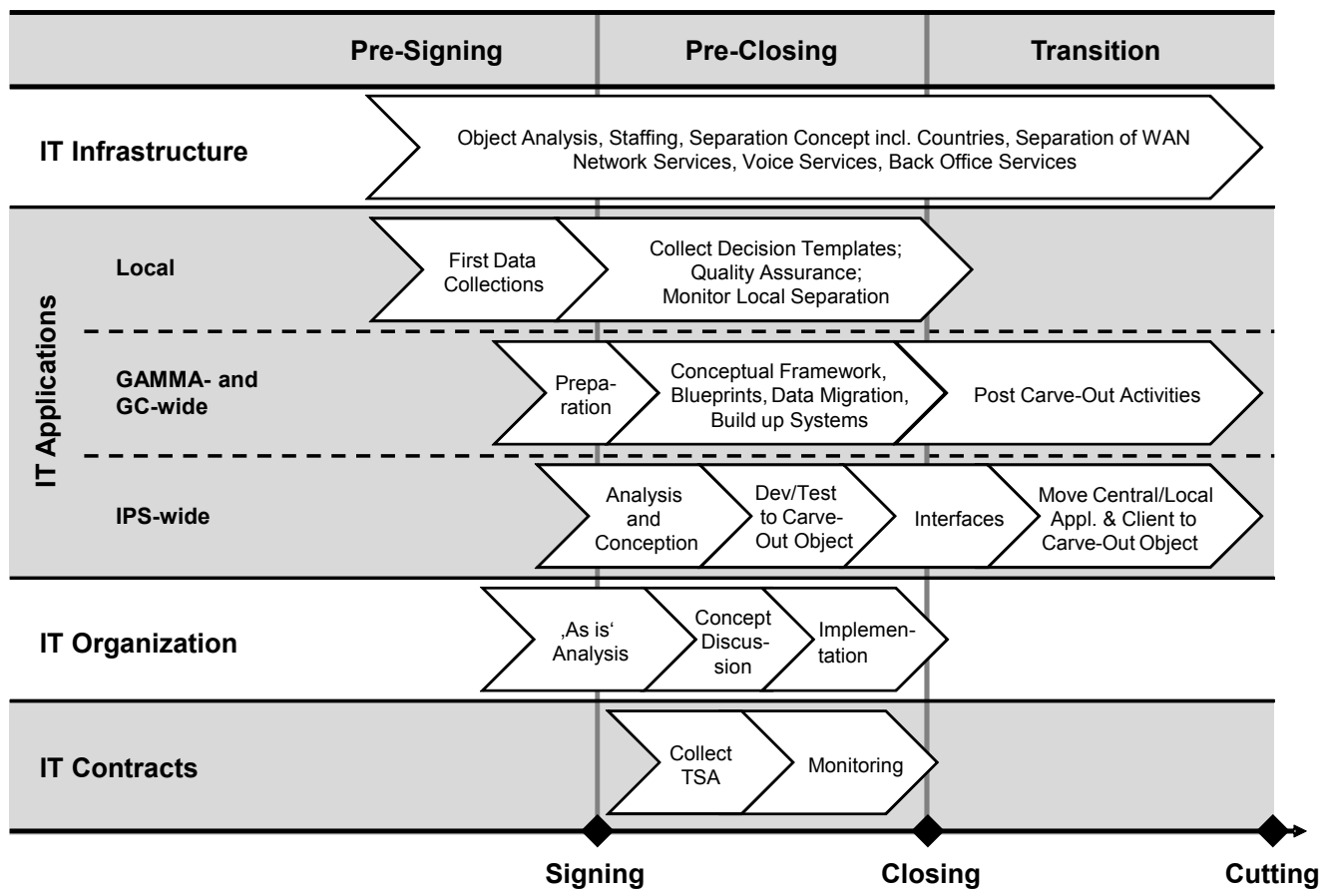

systems. So we have to work out how to identify the relevant IT systems and how to cut them out of our overall IT platform. But remember, even those IT systems that are IPS-specific and are managed by IPS, may also be used by other businesses in GC."

In particular, the partitioning of services across the IT lifecycle between the three GC business units had resulted in many system interdependencies between IPS and the other two business units. For example, a scheduling and billing system was used by all three business units. This system was developed by IPS and then adopted by IOS and ISS to improve cost transparency and to simplify customer billing across the three business units.

To identify all affected applications, the IT carve-out team developed the information template presented in Table 2 and established a database to collect that information for GAMMA-level, GC-level and IPSlevel applications under central and local control. To collect the information quickly, the IT workstream leader hired independent consultants. Having both consultants and the IT service providers available oncall enabled this task to be completed on time. Based on that information, a formal justification for retention was required for each application.
Migration decisions were made in collaboration with the buyer. There were three possible outcomes for each application:

- Refusal: application was not migrated, containing costs to the seller for redundant work

- Smooth-Migration: replace GAMMA components on GAMMA systems with I\&G components, resulting in shorter outages to both the buyer and the seller

- New-Installation: install I\&G components on new systems, ensuring homogeneous client infrastructure for the buyer, but potentially increasing migration costs to the seller.

The primary criteria for deciding between the Smooth-Migration and New-Installation options were the importance to the IPS business of a country and whether I\&G already had a presence there. The reasons for each decision were documented for traceability, and signatures were obtained from both GAMMA and I\&G executives to symbolically reinforce the collaborative nature of the decision making.

In the Transition phase, the absence of complete documentation of the customized local IT applications by country subsidiaries became an increasingly 


\section{Table 2: Information Template for Identifying Applications to be Retained}

- Name of the application

- Frequency of use

- User groups

- Age of the application

- Underlying and used technology

- Input data from other systems used by the application

- Application architecture (standalone or highly integrated)

- Business relevance (business critical or business support for IPS)

- Number of licenses

- Application owner

- Location where the application is used and hosted

- Justification for application use (reason for keeping application alive at IPS)

important issue. Subsidiaries had developed customized applications, so called "shadow IT," and had not documented the process for integration into the GAMMA Group's IT landscape. As a result, the IT workstream team had limited information on how these systems would be affected by the carve-out, and even which data was necessary to keep the businesses operational. One of the IT workstream members commented:

"In some cases, we could only pull out a system and watch what happened."

To address the shadow IT challenges, the IT workstream leader created a Country Coordination sub-stream (see Figure 3) to manage the problems resulting from incomplete documentation of applications specific to a country subsidiary. A dedicated Country Coordinator, responsible for status reporting and communication across all the affected countries, was appointed. This helped to establish trust between the parties involved and simplified access to information about local IT systems: there was one "go to" person. The Country Coordinator had a direct contact person in each country-typically the CIO of the country subsidiary - and weekly meetings were established to find solutions to isolate each country-specific IPS system from the GAMMA Group corporate IT platform.

IPS-wide applications were transferred to $I \& G$ at Closing. Where GAMMA-wide and GC-wide applications supported the business operations of the carve-out object, GC and GAMMA Group provided those applications and support services in the Transition phase, based on TSAs with I\&G. After technical and content preparation at both GAMMA/ $G C$ and $I \& G$, interfaces for data transfer were agreed upon and implemented, and all relevant applications were moved to $I \& G$.

IT Organization/Human Resources. Critical knowledge about the IPS IT landscape and processes began to "walk out the door" as rumors about the divestiture first surfaced. The IT workstream leader dedicated a team to preserving the IT capabilities required by the carve-out project, the IT organization for GC post-carve-out and the staff to be transferred to $I \& G$ as per the contractual obligations. One of the first steps was to audit and document the critical IT knowledge and capabilities. This also helped to reduce the risk that critical capabilities or tacit knowledge were lost because their importance went unrecognized. The incentive programs were defined with as wide a scope as possible to motivate people either to stay in their current position or to transfer to the buyer.

IT Contracts. Since full physical separation could not be achieved before the Cutting milestone, TSAs were established with the buyer for GC and GAMMA Group to provide support services for the information systems still under their control. The challenge for GC was to ensure that the buyer would not gain access to data from its other business units (IOS and ISS). The challenge for I\&G was to ensure that GC would not be able to access any new data about the carve-out object after Day One. 


\section{Table 3: Summary of Lessons Learned}

\section{Managing Carve-out Projects}

1. Build collaboration between the seller's carve-out team and the buyer's integration team

2. Allocate resources dynamically, leveraging external resources

3. Devote special attention to local differences

4. Design flexibility into Transitional Service Agreements

5. Establish a dedicated team to manage retention and support personnel transfers

\section{Creating a Divestiture-ready IT Environment}

6. Facilitate awareness of business dependencies on IT

7. Include IT leaders in strategic decision-making teams

8. Routinely review IT standardization and customization trade-offs

9. Maintain full and up-to-date documentation on the IT landscape

10. Include retention clauses in contracts for key IT personnel

Upon the Transition and Post-Cutting phases, the number of TSAs was continuously reduced until full physical separation was achieved and all IPS systems at GC were shut down. Interfaces for data transfer were agreed upon and implemented, and all relevant applications were transferred to I\&G. However, GC did incur significant carve-out costs from supporting the TSAs because it could not shut down otherwise redundant systems. In addition, some reverse TSAs had to be established with the buyer to allow the two other GC business units to use information systems formerly provided by IPS, until adequate replacements were implemented.

Another important activity of the IT Contracts sub-workstream was to ensure that GAMMA, GC and IPS remained compliant with their software license agreements after the carve-out. To do this, a team determined whether licenses could simply be transferred or whether they needed to be renegotiated. The team was also responsible for examining and renegotiating service contracts with third-party suppliers.

\section{LESSONS LEARNED}

The overall carve-out of IPS and the IT carve-out project were perceived as successes by both GAMMA Group and the buyer. Both parties achieved their strategic objectives, and both finished the projects within the planned time frames and budget constraints. From this experience, 10 important lessons were learned. They are summarized in Table 3 under two headings: Managing Carve-out Projects and Creating a Divestiture-ready IT Environment.

The weights to be given to the different lessons will depend on the divestiture context. In the IPS carveout, the buyer was a business partner and customer retention was critical to both the buyer and seller, so there was a higher existing degree of mutual trust, and a need for ongoing collaboration than might generally be true. In the IPS case, Lesson 1 below was therefore critical to the success of both the carve-out project by the seller and the subsequent integration project by the buyer. While collaboration is always important to capture joint benefits in a divestiture by one multibusiness organization and its integration into another, this case illustrates how the importance of a given lesson is contingent on the specific context.

\section{Managing Carve-out Projects}

1. Build Collaboration Between the Seller's Carveout Team and the Buyer's Integration Team. GC established 10 workstreams that had some overlapping responsibilities for information collection and key personnel retention, both with each other and with the complementary workstreams in the buyer's integration 
team. Establishing open communication and close collaboration across the carve-out and integration teams can reduce redundant work and carve-out costs, and create a partnership environment that fosters flexibility. ${ }^{8}$

IT carve-out projects are almost always subject to ongoing negotiations between the seller's and buyer's project managers to translate the contract into action. A protocol in which unanticipated costs and windfall benefits are shared between the seller and the buyersuch as between the contractor and the client in the construction industry - could help build collaboration.

For the IPS carve-out, the buyer initially had a dealmaking advantage because no IT representatives were included in the GAMMA Deal team. However, with open communication and close collaboration between GC and the buyer, contractual weaknesses were renegotiated and service agreements were modified as more information became available about system dependencies and realistic milestone dates.

2. Allocate Resources Dynamically, Leveraging External Resources. Consultants and IT service providers are typically available at short notice and can be used to dynamically resource IT activities to help meet deadlines. In addition, external resources may have valuable experience with other divestitures, which can be used to reduce both the seller's and the buyer's learning curves, and avoid the IT workstream becoming a bottleneck.

\section{Devote Special Attention to Local Differences.} Divestitures are typically top-level decisions with no upfront involvement and commitment from local unit managers. The greater the autonomy given to local managers pre-divestiture, the greater the need to dedicate resources to understand and document relevant local system interdependencies and to anticipate their impacts on the carve-out project and local business operations.

\section{Design Flexibility into Transitional Service} Agreements. Well-designed TSAs can be effective mechanisms for managing the Post-Closing phases of a divestiture when data and applications need to be available to the carve-out object, but are not yet physically separated from the seller's IT landscape. However, poorly designed TSAs can impose cost and security risks on the seller. This is especially true for a seller with limited capabilities and experience in

8 Böhm, M., Henningsson, S., Leimeister, J.M., Yetton, P., and Krcmar, H. "A Dual View on IT Challenges in Corporate Divestments and Acquisitions," 2011, Proceedings of the International Conference on Information Systems (ICIS), Shanghai, China, p. 20. providing external IT services. Technical measures can be taken to minimize the IT security risks, but poorly designed and managed TSAs can lock the seller into the status quo, limiting its strategic options in the short term.

To ensure that the buyer would not gain access to unauthorized data, GAMMA Group provided services to $I \& G$ on logically separate systems, to be accessed by the buyer through secure networks. To minimize the extent that TSAs decreased GAMMA Group's flexibility and locked them into additional costs, every effort was made to restrict the number of TSAs that were not completed before the Cutting milestone.

\section{Establish a Dedicated Team to Manage} Retention and Support Personnel Transfers. An HR team must be appointed at the outset of a carve-out to minimize departures and maximize retention of key personnel. Otherwise, scarce critical resources "walk out the door." The team should be given the authority to negotiate customized incentive packages for key personnel for the carve-out project and for postcarve-out positions in both the buyer and the seller. Providing this help to the buyer supports the culture of collaboration.

When rumors first began to circulate, some of the GAMMA employees who would be affected started to look for alternative jobs within GAMMA Group or externally. This was especially true in the country subsidiaries, where local application owners quickly changed their jobs or left the company. This increased the challenge to obtain the required information about the customized local applications and their dependencies. As soon as this risk was identified, lump-sum retention packages were offered to key managers, with individually negotiated retention packages agreed for other key personnel.

A more successful strategy would be to anticipate such risks as part of a divestiture-ready IT environment, as described below.

\section{Creating a Divestiture-ready IT Environment}

6. Facilitate Awareness of Business Dependencies on IT. Awareness by top management and the board of the importance of IT is critical to the success of a carve-out strategy. The executive team at GC recognized that IT was critical to the success of the carve-out project. This recognition was an outcome of prior actions by GC's CIO that had created an awareness of IT's critical interlinking role to support 
the company's business processes. Business leaders will appropriately resource a carve-out strategy only if they recognize critical IT dependencies and anticipate IT costs.

7. Include IT Leaders in Strategic Decisionmaking Teams. CIOs who regularly participate in strategic decision-making teams are less at risk of being excluded from divestiture decisions. Including leaders with a good overview of the IT environment in the Deal team ensures that IT-relevant information is part of due diligence and subsequent negotiations. Otherwise, the direct and indirect costs of postClosing TSAs can become significant and dilute the benefits of the carve-out.

IT leaders can also avoid the "same systems trap"i.e., where the same standard software is in use by both the buyer and seller-which can cause negotiators to underestimate the carve-out challenges and costs. Both GAMMA and I\&G used SAP systems for enterprise resource planning and financial reporting. However, these systems were highly customized and integrated. Apart from lower training costs for users of the systems, no benefits could be leveraged from having the "same system," because the SAP systems were, in effect, different customized solutions.

The contract for the divestiture of IPS favored the buyer because of the participation of IT leaders in the buyer's Deal team but not in the seller's Deal team. The absence of relevant IT clauses resulted in GC having to absorb substantial IT costs that should have been the responsibility of, or shared with, the buyer.

8. Routinely Review IT Standardization and Customization Trade-offs. Development of a divestiture-ready IT environment requires a structured approach to enterprise architecture management prior to the carve-out, including IT and business leader reviews to determine when standard applications are appropriate and when significant customization is required. Achieving the right balance keeps operational IT costs down and simplifies future carveouts.

\section{Maintain Full and Up-to-date Documentation on the IT Landscape. Divestiture-ready} organizations maintain adequate documentation of their IT landscapes as part of their overall enterprise architecture management strategies. Information from enterprise architecture management can be a valuable source for the due-diligence process, contract negotiations and the subsequent carveout project. Enterprise architecture management provides an overview of the IT landscape and its IT interdependencies. In a multinational organization, the risks of inadequate documentation at local levels are especially high. ${ }^{9}$

GAMMA Group, GC and the IPS business unit gave high degrees of freedom to the country subsidiaries to customize business applications to local conditions. The inadequate documentation of those systems, including some shadow IT systems, increased the complexity and cost of the IT carve-out project.

\section{Include Retention Clauses in HR Contracts} for Key IT Personnel. To proactively anticipate the need for retaining key IT personnel if a business unit in which they work is divested, retention incentives could be incorporated into existing contracts for these key IT players. Contract clauses could take the form of short-term incentives to keep these key people "onboard" during a future carve-out and for a limited period following the Cutting milestone.

\section{CONCLUDING COMMENTS}

GAMMA Group now has standard routines for its divestiture activities, and has also increased its divestiture readiness. Both have been important for an organization that strategically repositions itself by selling (and buying) business units. Although the relative importance of the lessons learned highlighted in this article is contingent on the divestiture context, we believe that these insights will be useful to other firms in a wide range of industries.

\section{APPENDIX: RESEARCH METHODOLOGY}

The authors have been working with GAMMA Group and Gamma Consulting for more than two years. In conducting this case study, several qualitative methods were adopted to identify how GAMMA Group and GC coped successfully with the divestiture of a business unit and the related IT challenges. The methods ranged from multiple, in-depth, semi-structured interviews, to expert focus groups comprising executives from the seller, buyer and carve-out object. In addition, GAMMA Group gave access to relevant archival material that documented its approach to managing IT in a divestiture. This material included presentations, technical and project

9 Böhm, M., Nominacher, B., Fähling, J., Leimeister, J.M., Yetton, P., and Krcmar, H. "IT Challenges in M\&A Transactions - The IT CarveOut View on Divestments," 2010, Proceedings of the International Conference on Information Systems (ICIS), St. Louis, p. 105. 
documentation, and other documents such as press releases and public announcements. We would like to thank GAMMA Group, GC and their managers for their support.

The case is part of a large research program on carveouts, with findings presented at international academic conferences (ECIS 2008, 2009 and 2010; ICIS 2010 and 2011).

\section{ABOUT THE AUTHORS}

\section{Jan Marco Leimeister}

Jan Marco Leimeister (leimeister@uni-kassel.de) is a Full Professor and Chair for Information Systems at Kassel University, Germany. He is affiliated with the Business School and the Computer Science Department and is Director of the IS Research Centre ITeG at Kassel University. Jan Marco heads research groups on service, collaboration and IT innovation engineering, and manages several large publicly funded and industry funded research projects. His teaching and research areas include strategic IT management, IT innovation management, service science, collaboration engineering, and ubiquitous and mobile computing.

\section{Markus Böhm}

Markus Böhm (markus.boehm@in.tum.de) is a research associate in the Krcmar Chair for Information Systems Department, Technische Universität München, Germany. He studied information systems at Friedrich-Alexander Universität Erlangen-Nürnberg (FAU), Germany, and at Jönköping International Business School (JIBS), Sweden. He focused on general management, IT and business process management, and software engineering. He has worked as an intern for BMW, Bosch, ContentServ and Siemens. Prior to his studies, he undertook an apprenticeship in business administration at Wolf $\mathrm{GmbH}$, and also worked in HR. His research interests include information management, IT-related challenges in mergers and carve-outs, and IT-enabled value webs.

\section{Philip Yetton}

Philip Yetton (p.yetton@unsw.edu.au) is Professor of Management at the Australian School of Business. $\mathrm{He}$ is the Otto Monstead Visiting Professor at the Copenhagen Business School, Peter Moore Research Fellow at the Said School of Business at Oxford University, and has been collaborating with the Krcmar Chair at Technische Universität München, Germany, for four years. His research interests include the role of IT in M\&As, IT and business strategic alignment, strategic IT leadership and common method variance. 